\title{
INFLUENCE OF THE DIGITAL DIVIDE AND SOCIO-ECONOMIC FACTORS ON PREVALENCE OF DIABETES
}

\author{
Loknath Sai Ambati, Dakota State University, loknathsai.ambati@trojans.dsu.edu \\ Omar El-Gayar, Dakota State University, omar.el-gayar@dsu.edu \\ Nevine Nawar, Alexandria University, nawarnh@yahoo.com
}

\begin{abstract}
More than 100 million Americans have diabetes or prediabetes (29 and 84 million, respectively). Factors such as overweight, sedentary behavior, and history of diabetes in the family have been commonly associated with the onset of type 2 diabetes. Extant literature now points to the effect of socio-economic factors such as education, income, ethnicity, and physical location on the prevalence of the disease. This research aims to investigate the impact of social determinants on diabetes with a particular emphasis on the digital divide. We used data from the Centers for Disease Control and Prevention (CDC) for diagnosed diabetes prevalence, obesity prevalence, and leisure time physical inactivity data for the year 2013 by county. We contrasted the diabetes prevalence data against social factors such as race, educational attainment, income, poverty, unemployment, and digital divide obtained from the US Census Bureau data. Used bivariate, multivariate and regression analysis reveals a statistically significant relation between the prevalence of diabetes and digital divide, race, education, income and unemployment rate, obesity prevalence, and leisure time physical inactivity $(P<0.000)$. Overall, the results demonstrate the significant role of the digital divide in influencing chronic conditions such as diabetes.
\end{abstract}

Keywords: Social determinants of health, digital divide, diabetes, population health

\section{INTRODUCTION}

Chronic diseases are the leading causes of death and disability in the United States driving the nation's $\$ 3.3$ trillion in healthcare expenditure every year (CDC, 2018). Diabetes is one of the life-threatening chronic diseases not only due to its prevalence but also due to its negative social and economic effects on the people who are affected. Type two diabetes is the most common form of diabetes and results when the body no longer responds to insulin or does not produce enough of it to maintain normal glucose levels. Approximately, $90 \%-95 \%$ of people with diabetes have type 2 and prediabetes can develop into type 2 but not type 1 (CDC, 2020). People with diabetes are highly prone to heart disease, stroke, kidney disease, eye problems, dental disease, nerve damage and foot problems (What Is Diabetes?, 2016).

Social determinants of health (SDOH) comprise of social and economic conditions involved in shaping the health status of individuals and communities (Marmot, 2005). SDOH include social and economic variables such as, but not limited to, access to education, access to health information, job opportunities, access to transportation, access to health services, ethnicity, age, social support from family and friends and income. SDOH are slowly being recognized as potential variables in shaping individual's health. Although every socio-economic factor is important, the digital divide tend to be a bridge between the socio-economic factors and the health status, the digital divide is often used to explain the lack of access or decreased access to information technology (IT). The digital divide can be of different forms such as access to broadband internet connection, access to laptop or smartphone, and access to health information.

Prior research suggests that socioeconomic factors show a significant effect on diabetes among other chronic conditions (Southerland et al., 2018). With the prominence of the digital divide as a factor that plays a key role in the maintenance and management of health and wellness (Lustria et al., 2011), the objective of this research is to extend prior research related to the social determinants of diabetes to particularly focus on the role of digital divide in diabetes prevalence. The findings of the research extend the understanding of the role of the digital divide in health and wellbeing with a particular focus on diabetes prevalence. Further, the findings inform public policy regarding the 


\section{Issues in Information Systems}

Volume 21, Issue 4, pp. 103-113, 2020

importance of addressing the digital divide in the quest towards the increased utilization of information technologies for improved health and wellbeing.

The remainder of the paper is organized as follows. Section II provides a brief background and highlight related research exploring the social determinants of diabetes and signifying the importance of investigating the effect of the digital divide and other SDOH on diabetes prevalence. Section III describes the research methodology while section IV presents the results obtained from the empirical analysis. Section V discusses the key findings obtained from this research and how the results complement extant literature. The final section concludes the paper with a summary of key findings, limitations, and directions for future research.

\section{LITERATURE REVIEW}

The social life of a person plays a key role in determining the degree of susceptibility, risk of exposure, course, and outcome of a disease irrespective of the type of disease. Socio-economic factors are no longer viewed as secondary factors affecting the health of an individual, but as the primary research focus of today's health perspective (Cockerham et al., 2017). The health and wellbeing of an individual or a population are interdependent on a broad number of socio-economic factors, these various types of factors are, but not limited to: natural environment, macrosocial factors (ideologies, political and historical conditions), inequalities (wealth and employment opportunities), built environment (public resources available and transportation), social context (policies, enforcement of ordinances and regulations), stressors (crime rate, safety, neighborhood and housing conditions), health behaviors, social integration and social support (Schulz \& Northridge, 2004). Some studies have argued that there is a direct causal effects on health by social factors along with the biological factors and demonstrated that the biological factors alone are not enough to control and remedy the disease (Cockerham, 2007).

Studies show a strong relation between socio-economic factors and the prevalence of diabetes in the United States and elsewhere (Whiting et al., 2010). The most frequently cited factors are age, educational level, job status, neighborhood, poverty level, race, and income (Tol et al., 2013; Walker et al., 2014). Interventions to control obesity would be more promising when the social environment at a community level (neighborhood) is addressed along with the direct factors (Cohen et al., 2006). Educational attainment is another important factor which has a potential influence on health disparities especially educational participation and academic performance (Jackson, 2009). Some studies demonstrated that unemployment or precarious work conditions have negative effects on health and wellbeing especially in younger people (Vancea \& Utzet, 2017). Other studies investigated the causal effects of income on health conditions and found strong evidence suggesting a causal relationship between income inequality and health and wellbeing (Pickett \& Wilkinson, 2015). Racism is a system of social stratification when combined with other socioeconomic factors, influence the population health and wellbeing (Williams et al., 2016).

Further, the digital divide appears to play a key role in affecting the health status of an individual (Wyatt et al., 2005). The most common attributes that can be employed to measure digital divide and its effect on the health and wellness include the availability of Internet access or subscription, access to or ownership of a computer or laptop or mobile device, usage of Internet for health information purposes, and e-healthcare usage (Chang et al., 2004; DenizardThompson et al., 2011; Powell et al., 2003; Sarkar et al., 2011). Despite the importance of the digital divide as a social determinant of health, there is apparently no research that explored the relationship of such factor on the prevalence of diabetes. This represents a significant research gap given the prominence of IT-based initiatives for the selfmanagement of diabetes (El-Gayar et al., 2013) as well as the increasing role of IT in the promotion and support for health and well-being through disease prevention and the promotion of healthy lifestyles. Accordingly, this research aims to investigate the impact of the digital divide (among other social determinants) on diabetes prevalence.

\section{RESEARCH METHODOLOGY}

The methodology employs univariate and bivariate analysis for performing multiple linear regression by considering socio-economic factors, health risk factors, and digital divide as independent variables and diabetes prevalence as the dependent variable. The significant impact of socio-economic factors, digital divide, and health risk factors on diabetes prevalence is evaluated based on the p-values obtained for each independent variable when fitted with multiple linear regression. The following sections describe the underlying datasets used in the study and provide a detailed account of the analysis procedure. 


\section{Issues in Information Systems}

Volume 21, Issue 4, pp. 103-113, 2020

\section{Dataset Description}

Diabetes prevalence, obesity prevalence and leisure time physical inactivity data by each county dataset were retrieved for the year 2013 from the CDC. US Census Bureau data was obtained using American Fact Finder (AFF) tool, all the datasets retrieved from AFF are based on the American Community Survey (ACS) one-year estimates for the year 2013 by county. A total of eight datasets were selected from the US Census Bureau using AFF, namely Median Income In The Past 12 Months, Percent Of Households With A Broadband Internet Subscription, Types Of Computers In Household, Educational Attainment, Poverty Status In The Past 12 Months, Race, Hispanic Or Latino Population and Employment Status.

The diagnosed diabetes prevalence, obesity prevalence, and leisure time physical inactivity data for the year 2013 by each county in United States was obtained from the CDC. The data was associated with data on the social factors: race, income, education, internet subscription, access/ownership of laptop or computer or mobile phone, and unemployment for United States counties with a population of more than 65,000 obtained from the US Census Bureau for the same year 2013. The educational attainment variables were condensed into four variables namely "Education1" (Total; Estimate; Population 25 years and over - High school graduate or below), "Education2" (Total; Estimate; Population 25 years and over - Some college or associate's degree), "Education3" (Total; Estimate; Population 25 years and over - Bachelor's degree) and "Education4" (Total; Estimate; Population 25 years and over - Graduate or professional degree). All the data sets are merged based on the federal information processing standard (FIPS) code used to uniquely identify counties.

\section{Analysis}

Data cleaning was done by removing entries with missing values from the data and all the attributes were standardized for processing. Outliers were treated by using z-scores, where any county with z-score greater than 3 or less than -3 was considered an outlier and removed. Regression analysis was employed to identify and understand the most important predictor variables that contribute to the accurate prediction of the prevalence of diabetes. Bivariate, and multivariate analysis were used to verify the assumptions for linear regression.

Bivariate analysis was relied on the skewness, kurtosis, correlation matrix and scatterplots to explore normality, multicollinearity, and linearity, respectively. Using the correlation matrix and the correlation heat map, a value of correlation coefficient zero indicated no multi-collinearity between the predictor variables while a value of 0.8 and over indicated significant multi-collinearity between the predictor variables. Scatter plots were plotted for each variable in the dataset against the prevalence of diabetes (dependent variable). Based on the results obtained from the scatterplots and the correlation matrix, we removed highly correlated variables and variables which were not linearly related with the target variable. Skewness and kurtosis values were computed for each predictor variable. Logarithmic transformation and square root functions were employed to suppress extreme values. Variables having unusual skewness and kurtosis values after the treatment were deemed to fail the normality test and removed from the analysis.

Multivariate analysis was carried out to further verify multi-collinearity among the predictor variables using Variance Inflation Factors (VIF). Usually, if the value of VIF is one, then multi-collinearity does not exist among the predictor variables and as the value increases, the collinearity between the predictor variables increases. A VIF value of ten and over, indicates a definite multi-collinearity between the predictor variables, so we set the threshold value to be eight to allow for minimal collinearity between the predictor variables. Finally, homoscedasticity assumption was validated using Breusch-Pagan test.

Multiple linear regression was carried out on the resultant dataset using ordinary least squares (OLS). The identification of the significance of socio-economic factors and health risk factors assumed a significance level of 0.05 (95\% confidence interval). Fit was assessed using the adjusted $\mathrm{R}^{2}$.

\section{RESULTS}

The studied data consisted of 769 counties in the United States with 19 predictor variables and 1 target variable. Table 1 shows the descriptive statistics of the of the data. Figures 1 and 2 show the scatterplot results and correlation heat 


\section{Issues in Information Systems}

Volume 21, Issue 4, pp. 103-113, 2020

map results from the bivariate analysis. Figure 3 depicts the dependent variable (Diabetes Prevalence) by state with size of the block associated by Digital Divide (Household percentage of broadband subscription).

Two variables were dropped from the dataset, based on the results obtained from these plots. The variables broadband percent and computer ownership were highly correlated to each other and their scatterplot with diabetes prevalence were nearly identical, therefore we decided to drop the broadband percent variable. Similarly, Education1 was highly correlated with computer ownership as well as Education4, therefore we dropped the Education1 variable.

The remaining predictor variables were evaluated for normality using skewness and kurtosis values. American Indian and Alaska Native population, and Native Hawaiian and other pacific islander population variables had extreme skewness and kurtosis values even after the treatment. Moreover, the combination of these two races contribute to less than one percent of the US population. Therefore, these two variables were excluded from further analysis.

The remaining fifteen predictor variables were further tested for multi-collinearity using VIF. The variables White population and Black or African American population variables had VIF values greater than eight. Instead of removing these variables, we decided to remove Education4, Asian population and other race population variables due to their correlation with White and Black or African American population variables and the sparsity of data in the counties under consideration. The VIF values were computed again for the remaining predictor variables and we found that there was no significant multi-collinearity problem among the predictor variables. Using the Breusch-Pagan test on the remaining variables variable indicated that there was no significant heteroscedasticity.

Multiple linear regression was carried out with the remaining twelve predictor variables and one target variable. Figure 4 shows the obtained results from the linear regression analysis when all twelve predictor variables were employed against diabetes prevalence. The variables computer ownership, education variables, two or more races, and income were statistically not significant based on the $\mathrm{p}$-values $(\mathrm{P}>0.05)$. These results were examined, keeping the extant literature as reference to find the best set of predictor variables that contribute to the variance in diabetes prevalence.

Table 1. Descriptive Statistics

\begin{tabular}{|c|c|c|c|c|c|c|c|c|}
\hline & count & mean & std & $\min$ & $25 \%$ & $50 \%$ & $75 \%$ & $\max$ \\
\hline Broadband Percent & 758.0 & 73.35 & 7.87 & 29.8 & 68.82 & 73.80 & 78.77 & 91.9 \\
\hline Computer Ownership & 758.0 & 83.97 & 5.99 & 42.8 & 80.60 & 84.60 & 88.07 & 96.8 \\
\hline Education 1 & 758.0 & 41.08 & 9.20 & 12.7 & 35.10 & 40.90 & 47.18 & 68.0 \\
\hline Education2 & 758.0 & 30.68 & 4.81 & 12.9 & 27.70 & 30.80 & 33.70 & 45.6 \\
\hline Education 3 & 758.0 & 17.67 & 5.66 & 5.5 & 13.50 & 17.30 & 20.90 & 39.4 \\
\hline Education 4 & 758.0 & 10.57 & 5.01 & 1.9 & 7.10 & 9.65 & 12.90 & 39.1 \\
\hline Poverty & 758.0 & 15.46 & 5.76 & 3.2 & 11.52 & 15.40 & 18.90 & 42.4 \\
\hline White population & 758.0 & 78.79 & 14.74 & 17.3 & 72.30 & 82.35 & 89.80 & 96.5 \\
\hline Black or African American population & 758.0 & 10.99 & 12.32 & 0.0 & 2.60 & 6.40 & 14.58 & 70.8 \\
\hline American Indian and Alaska Native population & 758.0 & 1.08 & 4.77 & 0.0 & 0.20 & 0.30 & 0.60 & 74.7 \\
\hline Asian population & 758.0 & 3.17 & 4.27 & 0.1 & 1.02 & 1.90 & 3.70 & 42.6 \\
\hline Native Hawaiian and Other Pacific Islander population & 758.0 & 0.14 & 0.80 & 0.0 & 0.00 & 0.00 & 0.10 & 13.6 \\
\hline Other race population & 758.0 & 2.95 & 3.81 & 0.0 & 0.70 & 1.60 & 3.38 & 38.2 \\
\hline Two or more races & 758.0 & 2.87 & 2.07 & 0.5 & 1.80 & 2.50 & 3.40 & 28.3 \\
\hline Unemployment rate & 758.0 & 8.28 & 2.70 & 1.3 & 6.32 & 7.95 & 9.90 & 19.9 \\
\hline Income & 758.0 & 53615.80 & 13840.94 & 24945.0 & 43930.50 & 50667.00 & 59318.50 & 116848.0 \\
\hline Obesity prevalence & 758.0 & 28.82 & 4.46 & 13.3 & 25.90 & 29.10 & 32.10 & 42.3 \\
\hline Leasure time physical inactivity & 758.0 & 22.18 & 4.45 & 8.8 & 19.00 & 22.10 & 25.37 & 33.7 \\
\hline Hispanic or Latino Population & 758.0 & 11.80 & 13.42 & 0.5 & 3.90 & 6.90 & 13.88 & 95.3 \\
\hline Diabetes Prevalence & 758.0 & 9.24 & 1.78 & 3.9 & 8.00 & 9.10 & 10.40 & 14.9 \\
\hline
\end{tabular}




\section{Issues in Information Systems}

Volume 21, Issue 4, pp. 103-113, 2020
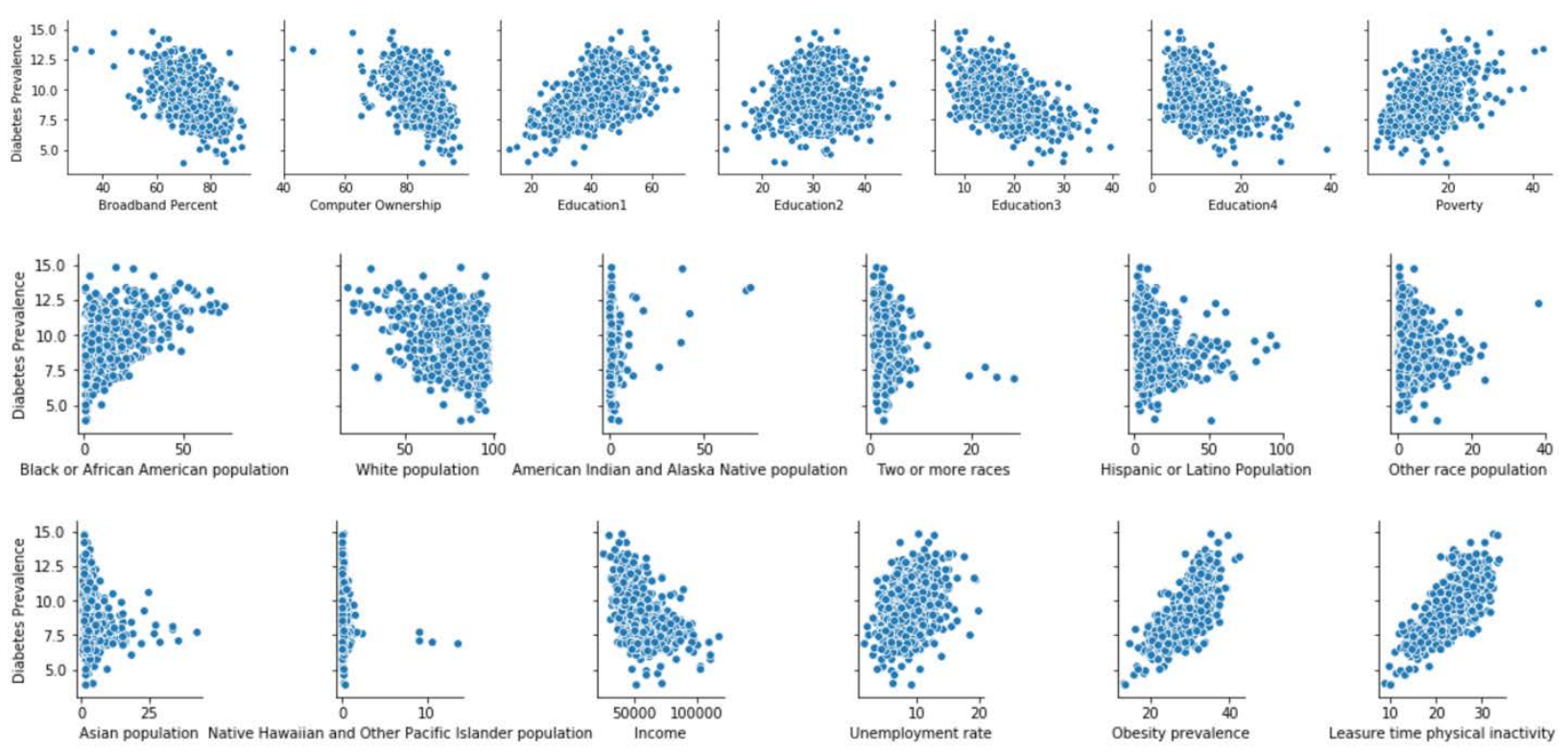

Figure 1. Scatter Plot Results

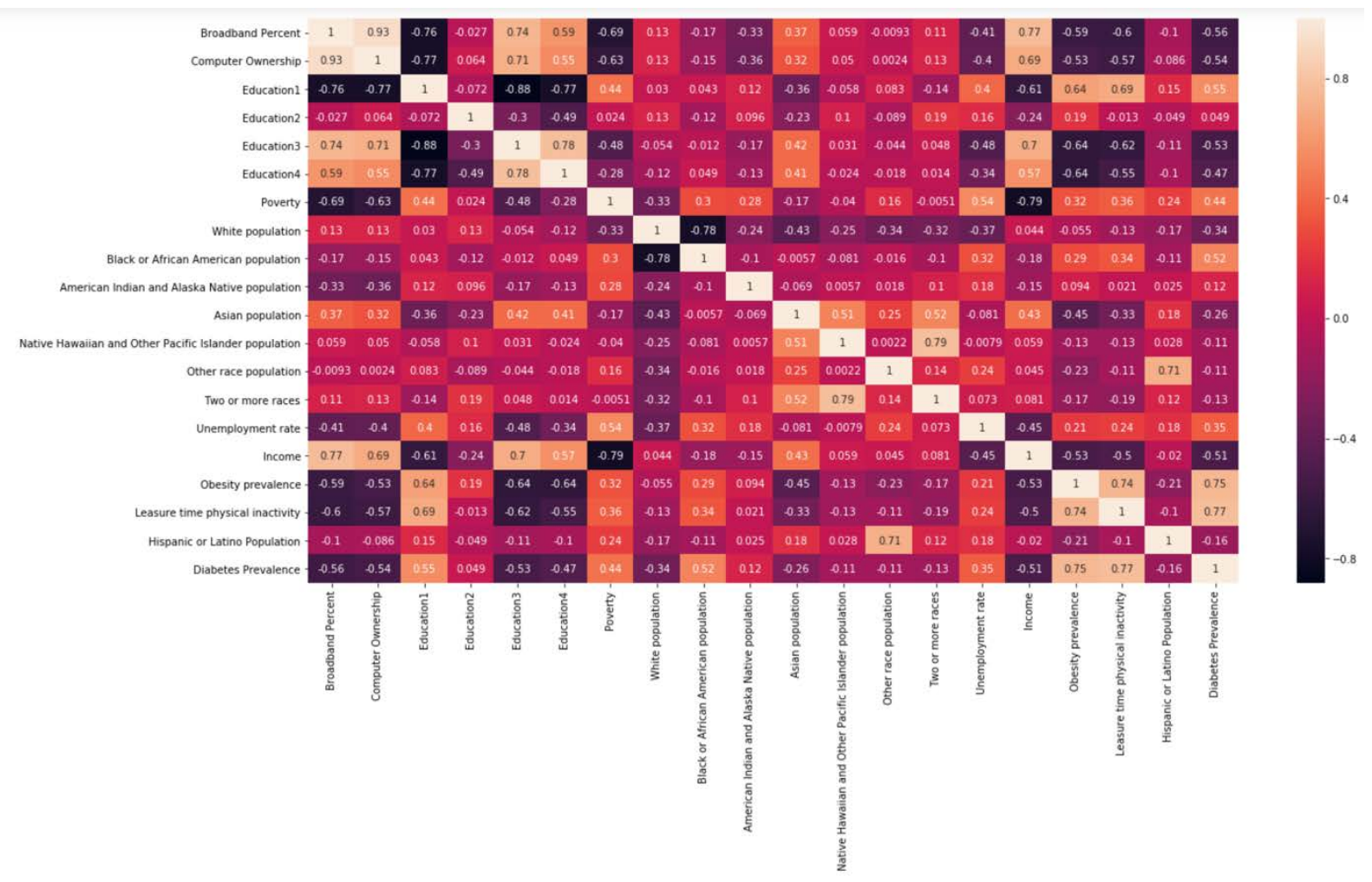

Figure 2. Correlation Heat Map of All the Variables 


\section{Issues in Information Systems}

Volume 21, Issue 4, pp. 103-113, 2020

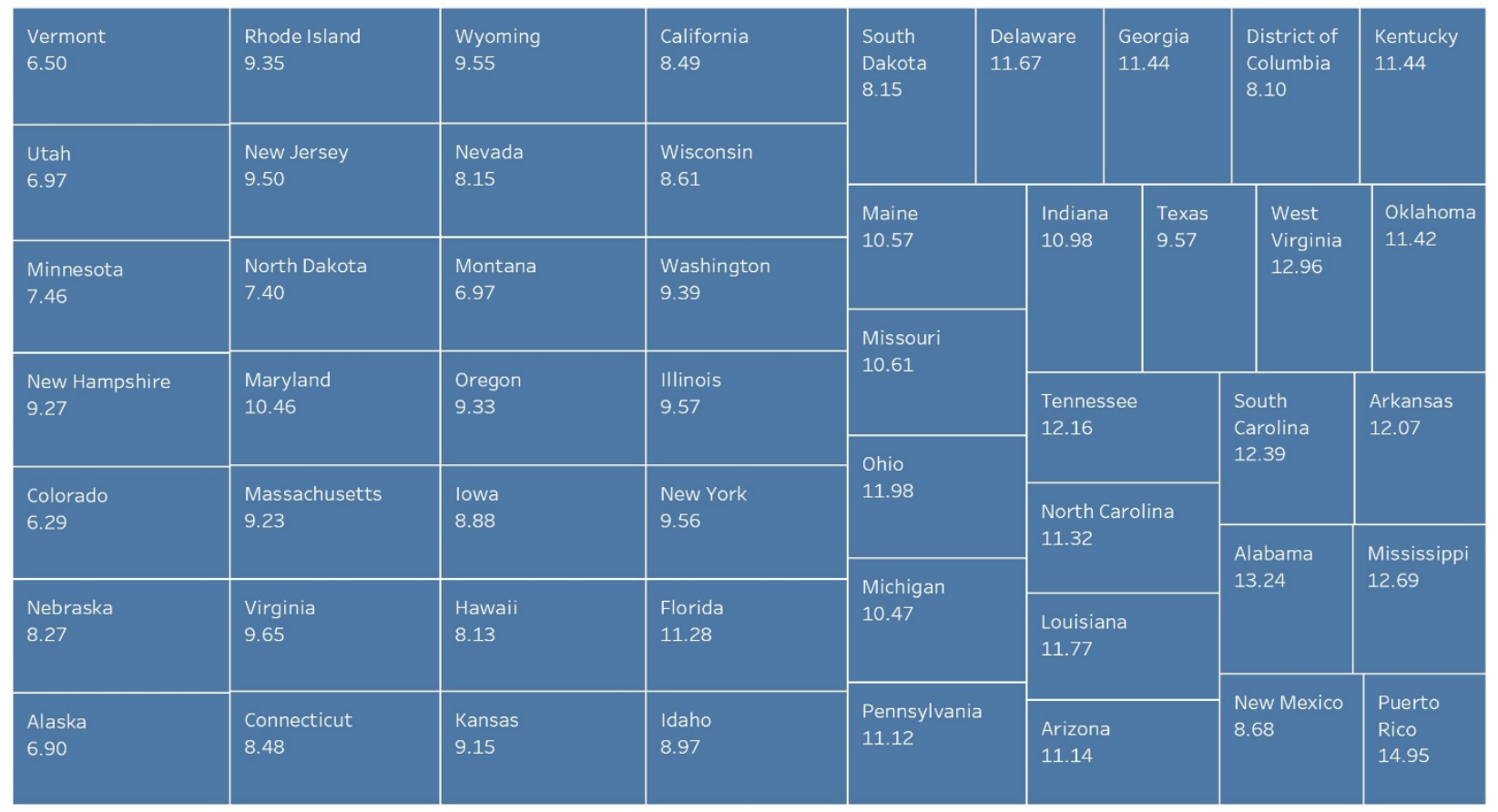

Figure 3. Diabetes Prevalence of Each State with Size of the Block Associated by Digital Divide (Household Percentage of Broadband Subscription)

Prior research shows evidence that the relationship between education and health is less prevalent while the combined effect of education and income-related variables show increased significance as a social determinants of health (Lynch, 2006). Further, education appears to contribute significantly in explaining income and poverty (Balamurali et al., 2015) while education and poverty are statistically significant in explaining unemployment rate (Lavrinovicha et al., 2015; Wiemers, 2014; Zedlewski \& Nichols, 2012). Further, since income, poverty and unemployment have moderate correlation among themselves and striving towards a parsimonious model, we removed education, income, and poverty while keeping the unemployment rate.

As shown in figure 4, the two or more races variable was not statistically significant. Given that it represented less than 3 percent of US population, we opted to exclude it from further analysis. According to the US Census, the Hispanic or Latino population figures contain other races that are identified as such but are Hispanic or Latino descendants, complicating the interpretation of the findings in the presence of other race variables. Hence, a number of studies that dealt with social determinants of health, either considered Latino or Hispanic variable or the other race variables in their final set (Gaskin et al., 2014; Siordia et al., 2012). Along these lines, we opted to remove Hispanic or Latino variable from further analysis. Moving further towards a parsimonious model and recognizing the correlation (> 0.7) among the remaining race variables in the data set, we decided to keep the Black or African American while removing the White population variable. Although Principle Component Analysis (PCA) method could be used to combine these two variables, it would have been difficult to interpret the results. 


\section{Issues in Information Systems \\ Volume 21, Issue 4, pp. 103-113, 2020}

OLS Regression Results

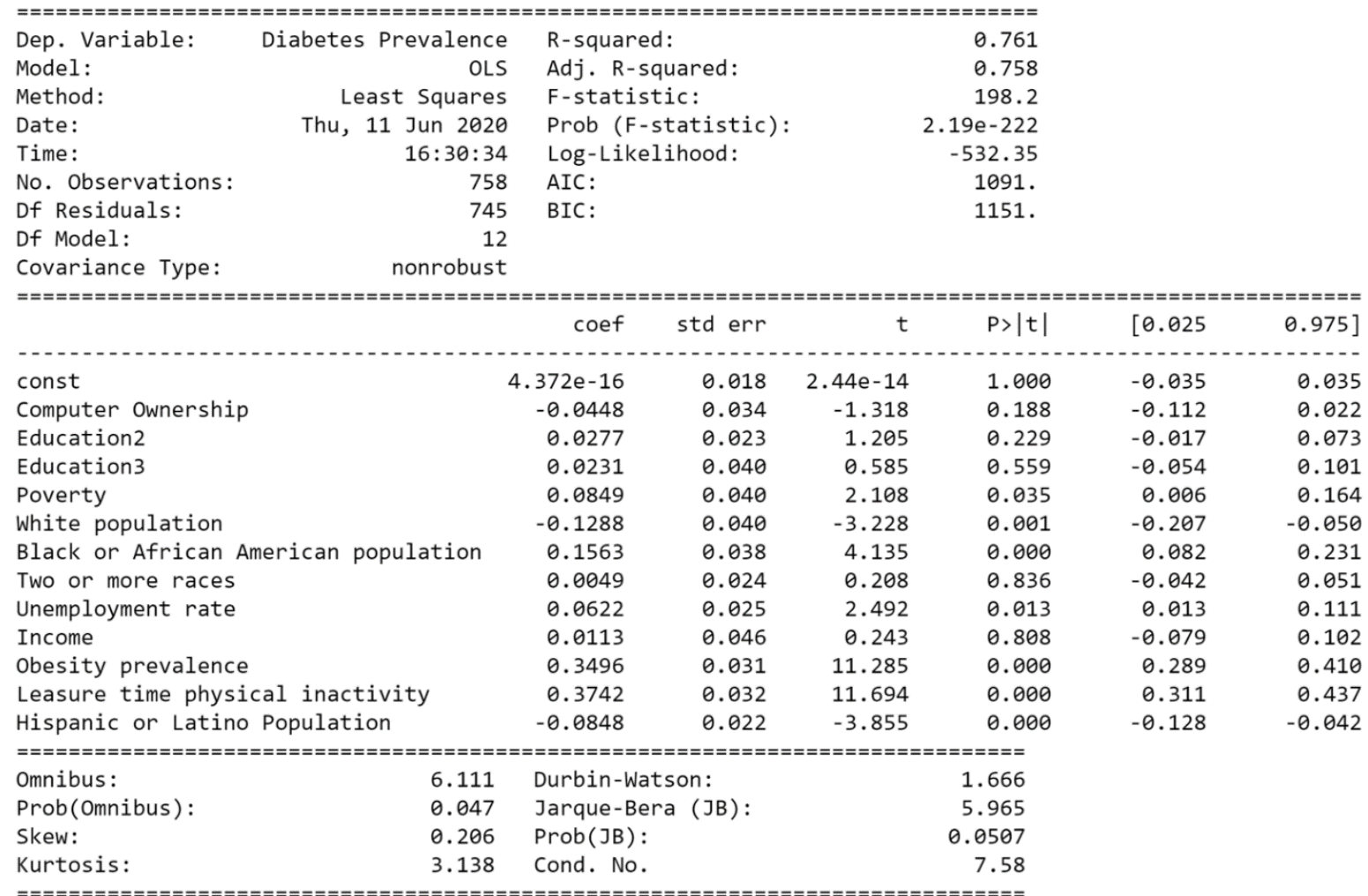

Figure 4. Initial Multiple Linear Regression Results

Multiple linear regression was performed with the remaining five predictor variables (Figure 5). All variables were significant $(\mathrm{P}<0.000)$ with digital divide (computer ownership) exhibiting a negative relationship with diabetes prevalence, while the rest of the predictor variables had a positive correlation with diabetes prevalence. The adjusted $\mathrm{R}^{2}$ showed dropped slightly from 0.758 to 0.748 .

OLS Regression Results

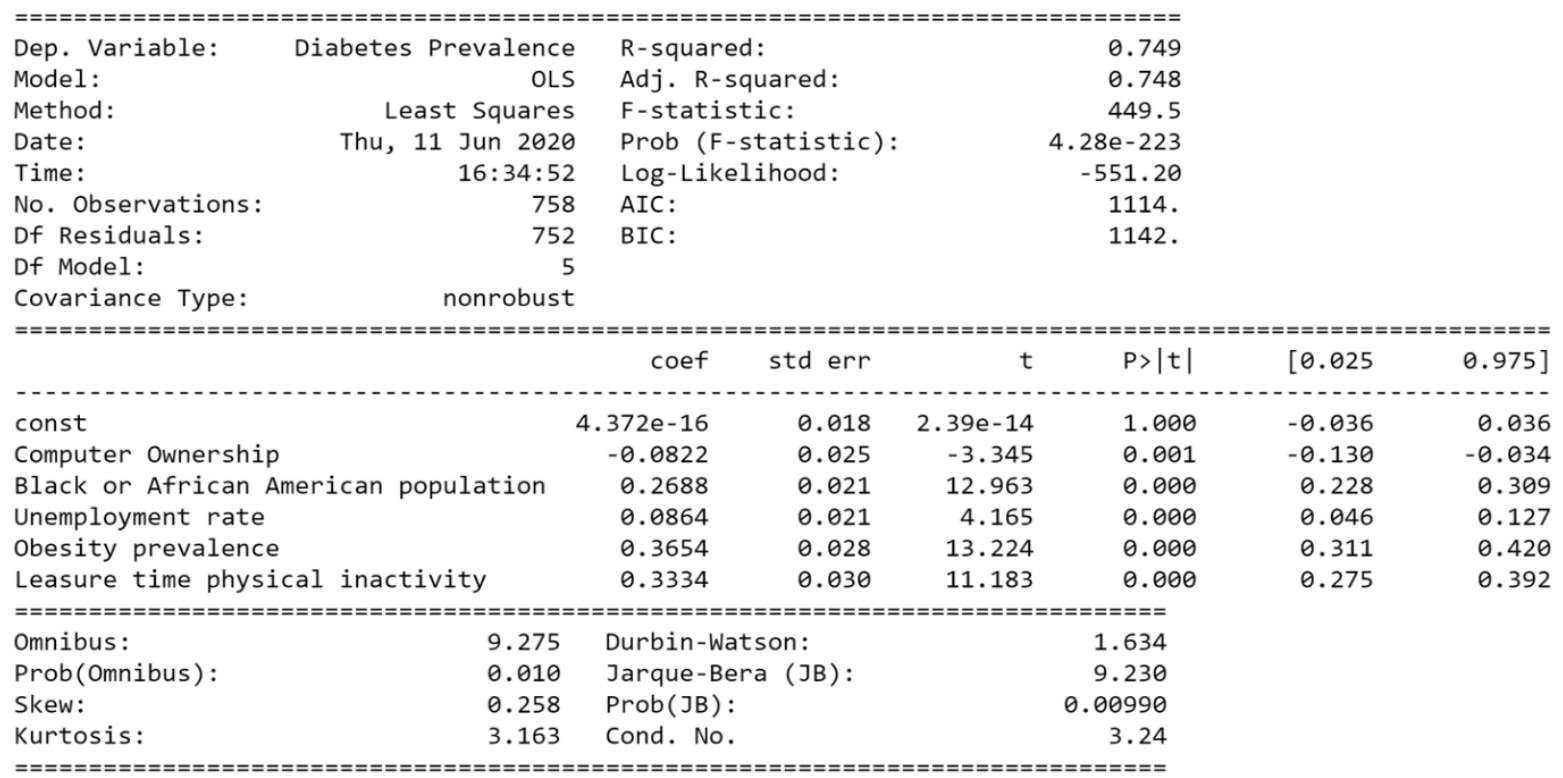

Figure 5. Final Multiple Linear Regression Results 


\section{Issues in Information Systems}

Volume 21, Issue 4, pp. 103-113, 2020

\section{DISCUSSION}

Figure 3 illustrates that, as the broadband percent increased, the prevalence of diabetes decreased. From the regression analysis, computer ownership was inversely related to diabetes prevalence. One possible explanation is that the access to the Internet and usage of a laptop or computer contributes to reducing the prevalence of diabetes by facilitating selfcare, access to health information, promotion of good health and wellness all leading to prevention of diabetes. The use of the Internet to search for information related to diabetes is gradually increasing (Nordfeldt et al., 2005).

In addition to the digital divide, unemployment rate adversely impacted diabetes prevalence. A probable explanation is the financial hardship and stress associated with unemployment potentially leading to unhealthy diet and lifestyle (New Research Shows Unemployment Is Related to Type 2 Diabetes In, n.d.). Both obesity prevalence and leisure time physical inactivity also demonstrated an adverse effect on diabetes prevalence. Recent studies on diabetes have shown that both of these factors individually affect diabetes prevalence and also combine with each other to affect diabetes (Qin et al., 2010).

Most diabetes interventions are focused on glycemic control, obesity control, physical activity, stress and anxiety reduction as major direct factors when designing a diabetes self-care and self-management intervention. However, the findings confirm the role socio-economic factors play in diabetes prevalence and thus the importance of accounting for such factors when designing preventive and treatment interventions. This is in line with prior research that signifies the importance of social factors in influencing the prevalence of diabetes (Hill et al., 2013). Overall, the findings confirm the need for stakeholders (healthcare providers, planners, government officials, politicians) to account for and actively mitigate socio-economic disparities that demonstrably affect individuals' health and wellbeing. Further, in this research, we were able to identify and demonstrate the importance of another social determinant of health, namely, the digital divide. With the increasing reliance on information technology (El-Gayar et al., 2013) for diabetes selfmanagement, recent development in the Internet of Things (IoT), and the ambitious vision for a smart and connected health, factors such as the digital divide (and in light of the findings of this research) are in effect critical success factors for the realization of effective IT-based interventions for diabetes self-care and self-management.

\section{CONCLUSION}

Socio-economic factors are no longer considered secondary or tertiary factors in influencing health outcomes, especially diabetes. The digital divide not only plays a key role in influencing the social factors but also the health and wellness of the population. Similarly, race, obesity prevalence, leisure time physical inactivity, and unemployment rate prove to be significant influencing factors for the prevalence of diabetes indicating the importance of lifestyle and social fundamentals in better health care and management. The results indicate the relationship of computer ownership (as a proxy for the digital divide) with diabetes prevalence. Future studies could further investigate socio-economic factors (such as access to rich and nutritious food and age) in conjunction with the digital divide. With the focus of the current research on a subset of US counties, future research could broaden the scope to include other US counties or countries (depending on data availability). It could also capitalize on the findings and explore the design of diabetes intervention strategies that accommodate some of the limitations imposed by the presence of such socio-economic factors. Overall, the efficacy of IT-based diabetes management interventions and the realization of the benefits of a connected health are inevitably contingent on the proactive mitigation of socio-economic disparities.

\section{REFERENCES}

Balamurali, A., Janflone, J., \& Zhu, E. (2015). The Impact of Education on Poverty. https://smartech.gatech.edu/handle/1853/54219

CDC. (2020, February 6). The Surprising Truth About Prediabetes. Centers for Disease Control and Prevention. https://www.cdc.gov/diabetes/library/features/truth-about-prediabetes.html

CDC, N. C. for C. D. P. and H. P. (2018, November 19). About Chronic Diseases | CDC. https://www.cdc.gov/chronicdisease/about/index.htm 
Chang, B. L., Bakken, S., Brown, S. S., Houston, T. K., Kreps, G. L., Kukafka, R., Safran, C., \& Stavri, P. Z. (2004). Bridging the Digital Divide: Reaching Vulnerable Populations. Journal of the American Medical Informatics Association, 11(6), 448-457. https://doi.org/10.1197/jamia.M1535

Cockerham, W. C. (2007). Social Causes of Health and Disease. Polity.

Cockerham, W. C., Hamby, B. W., \& Oates, G. R. (2017). The Social Determinants of Chronic Disease. American Journal of Preventive Medicine, 52(1 Suppl 1), S5-S12. https://doi.org/10.1016/j.amepre.2016.09.010

Cohen, D. A., Finch, B. K., Bower, A., \& Sastry, N. (2006). Collective efficacy and obesity: The potential influence of social factors on health. Social Science \& Medicine, 62(3), 769-778. https://doi.org/10.1016/j.socscimed.2005.06.033

Denizard-Thompson, N. M., Feiereisel, K. B., Stevens, S. F., Miller, D. P., \& Wofford, J. L. (2011). The Digital Divide at an Urban Community Health Center: Implications for Quality Improvement and Health Care Access. Journal of Community Health, 36(3), 456-460. https://doi.org/10.1007/s10900-010-9327-5

El-Gayar, O., Timsina, P., Nawar, N., \& Eid, W. (2013). A systematic review of IT for diabetes self-management: Are we there yet? International Journal of Medical Informatics, 82(8), 637-652. https://doi.org/10.1016/j.ijmedinf.2013.05.006

Gaskin, D. J., Thorpe, R. J., McGinty, E. E., Bower, K., Rohde, C., Young, J. H., LaVeist, T. A., \& Dubay, L. (2014). Disparities in Diabetes: The Nexus of Race, Poverty, and Place. American Journal of Public Health, 104(11), 2147-2155. https://doi.org/10.2105/AJPH.2013.301420

Hill, J., Nielsen, M., \& Fox, M. H. (2013). Understanding the Social Factors That Contribute to Diabetes: A Means to Informing Health Care and Social Policies for the Chronically Ill. The Permanente Journal, 17(2), 67-72. https://doi.org/10.7812/TPP/12-099

Jackson, M. I. (2009). Understanding Links Between Adolescent Health and Educational Attainment. Demography, 46(4), 671-694.

Lavrinovicha, I., Lavrinenko, O., \& Teivans-Treinovskis, J. (2015). Influence of Education on Unemployment Rate and Incomes of Residents. Procedia - Social and Behavioral Sciences, 174, 3824-3831. https://doi.org/10.1016/j.sbspro.2015.01.1120

Lustria, M. L. A., Smith, S. A., \& Hinnant, C. C. (2011). Exploring digital divides: An examination of eHealth technology use in health information seeking, communication and personal health information management in the USA. Health Informatics Journal, 17(3), 224-243. https://doi.org/10.1177/1460458211414843

Lynch, S. M. (2006). Explaining Life Course and Cohort Variation in the Relationship between Education and Health: The Role of Income. Journal of Health and Social Behavior, 47(4), 324-338. https://doi.org/10.1177/002214650604700402

Marmot, M. (2005). Social determinants of health inequalities. The Lancet, 365(9464), 1099-1104. https://doi.org/10.1016/S0140-6736(05)71146-6

New research shows unemployment is related to type 2 diabetes in. (n.d.). Retrieved November 20, 2019, from https://www.dynahealth.eu/news

Nordfeldt, S., Johansson, C., Carlsson, E., \& Hammersjö, J.-Å. (2005). Use of the Internet to search for information in type 1 diabetes children and adolescents: A cross-sectional study. Technology and Health Care, 13(1), 6774. https://doi.org/10.3233/THC-2005-13104 
Pickett, K. E., \& Wilkinson, R. G. (2015). Income inequality and health: A causal review. Social Science \& Medicine, 128, 316-326. https://doi.org/10.1016/j.socscimed.2014.12.031

Powell, J. A., Darvell, M., \& Gray, J. A. M. (2003). The Doctor, The Patient and the World-Wide Web: How the Internet is Changing Healthcare. Journal of the Royal Society of Medicine, 96, 74-76.

Qin, L., Knol, M. J., Corpeleijn, E., \& Stolk, R. P. (2010). Does physical activity modify the risk of obesity for type 2 diabetes: A review of epidemiological data. European Journal of Epidemiology, 25(1), 5-12. https://doi.org/10.1007/s10654-009-9395-y

Sarkar, U., Karter, A. J., Liu, J. Y., Adler, N. E., Nguyen, R., López, A., \& Schillinger, D. (2011). Social disparities in internet patient portal use in diabetes: Evidence that the digital divide extends beyond access. Journal of the American Medical Informatics Association, 18(3), 318-321. https://doi.org/10.1136/jamia.2010.006015

Schulz, A., \& Northridge, M. E. (2004). Social Determinants of Health: Implications for Environmental Health Promotion. Health Education \& Behavior, 31(4), 455-471. https://doi.org/10.1177/1090198104265598

Siordia, C., Saenz, J., \& Tom, S. E. (2012). An Introduction to Macro- Level Spatial Nonstationarity: A Geographically Weighted Regression Analysis of Diabetes and Poverty. Human Geographies, 6(2), 5-13. https://doi.org/10.5719/hgeo.2012.62.5

Southerland, W., Wright, J., Payne, D., \& Washington, G. (2018). LifeGrid: Understanding and Quantifying the Impact of Social Determinants on Chronic Disease for Predictive Health. 2018 IEEE International Conference on Healthcare Informatics (ICHI), 355-357. https://doi.org/10.1109/ICHI.2018.00054

Tol, A., Sharifirad, G., Shojaezadeh, D., Tavasoli, E., \& Azadbakht, L. (2013). Socio-economic factors and diabetes consequences among patients with type 2 diabetes. Journal of Education and Health Promotion, 2. https://doi.org/10.4103/2277-9531.108009

Vancea, M., \& Utzet, M. (2017). How unemployment and precarious employment affect the health of young people: A scoping study on social determinants. Scandinavian Journal of Public Health, 45(1), 73-84. https://doi.org/10.1177/1403494816679555

Walker, R. J., Smalls, B. L., Campbell, J. A., Strom Williams, J. L., \& Egede, L. E. (2014). Impact of social determinants of health on outcomes for type 2 diabetes: A systematic review. Endocrine, 47(1), 29-48. https://doi.org/10.1007/s12020-014-0195-0

What is Diabetes? | NIDDK. (2016, November). National Institute of Diabetes and Digestive and Kidney Diseases. https://www.niddk.nih.gov/health-information/diabetes/overview/what-is-diabetes

Whiting, D., Unwin, N., \& Roglic, G. (2010). Diabetes: Equity and social determinants. Equity, Social Determinants and Public Health Programmes, 77-94.

Wiemers, E. E. (2014). The Effect of Unemployment on Household Composition and Doubling Up. Demography, 51(6), 2155-2178. https://doi.org/10.1007/s13524-014-0347-0

Williams, D. R., Priest, N., \& Anderson, N. (2016). Understanding Associations between Race, Socioeconomic Status and Health: Patterns and Prospects. Health Psychology: Official Journal of the Division of Health Psychology, American Psychological Association, 35(4), 407-411. https://doi.org/10.1037/hea0000242

Wyatt, S., Henwood, F., Hart, A., \& Smith, J. (2005). The digital divide, health information and everyday life. New Media \& Society, 7(2), 199-218. https://doi.org/10.1177/1461444805050747 


\section{Issues in Information Systems}

Volume 21, Issue 4, pp. 103-113, 2020

Zedlewski, S., \& Nichols, A. (2012). What Happens to Families’ Income and Poverty after Unemployment? Urban Institute, 25, 9. 